\title{
A CROSS SECTIONAL STUDY ON MENSTRUAL HYGIENE AMONG ADOLESCENT GIRLS IN URBAN HEALTH CENTER FIELD PRACTICE AREA OF A MEDICAL COLLEGE IN WEST GODAVARI DISTRICT, ANDHRA PRADESH.
}

\author{
Shridevi $\mathrm{K}^{1}$, Padma $\mathrm{K}^{2}$
}

HOW TO CITE THIS ARTICLE:

Shridevi K, Padma K. "A cross sectional study on menstrual hygiene among adolescent girls in urban health center field practice area of a medical college in West Godavari district, Andhra Pradesh.". Journal of Evolution of Medical and Dental Sciences 2013; Vol2, Issue 34, August 26; Page: 6394-6401.

ABSTRACT: BACKGROUND: Awareness on menstruation and its problems during adolescent period is required to prevent increased incidence of reproductive tract infections and other problems. Hence the present study was conducted with the following. OBJECTIVES: 1 . To know the Pattern of menstruation among adolescent girls. 2. To know the knowledge, Attitude and Practices of menstrual hygiene among adolescent girls METHODOLOGY: Cross sectional study carried among $8^{\text {th }}, 9^{\text {th }} \& 11^{\text {th }}$ class of adolescent girls studying in Government school and college in urban field practice area of a medical college in west-Godavari district. Data was collected by Pre planned, Pretested and structured questionnaire and analyzed using Microsoft excel from were percentages and proportions were calculated. RESULTS: In the study, $13.07 \%$ have blood flow for more than 5 days, $16.8 \%$ have blood flow for cycle less than 28 days. $22.93 \%$ have excessive bleeding. Knowledge on menstruation before attainment of menarche was $6.13 \%$ but after menarche $80.27 \%$ of girls knew correctly that vagina is the route of menstruation. Regarding attitude $80.8 \%$ of the girls are interested to learn but feel shy to learn regarding menstruation. Regarding practices $74.4 \%$ were using sanitary pad and $99.2 \%$ of the girls practice personal hygiene. $68.01 \%$ dispose the pad in a satisfactory manner. CONCLUSIONS: $71.2 \%$ of girls have attained menarche at the age of 12-14 yrs. In the study $22.93 \%$ are suffering from Menorrhagia. Only $18.66 \%$ of girls knew regarding normal pattern of menstruation. $86.67 \%$ hesitate to discuss regarding menstrual problems.

KEY WORDS: Adolescence, menstrual hygiene, attitude, practices.

INTRODUCTION: Adolescence is the period between 10-19 yrs of life. Girls in this period constitute $1 / 5$ of the total population in the world ${ }^{2}$. This period has been recognized as a turbulent period which signifies, the transition from girlhood to womanhood and considered land mark for female puberty, which requires special and specific attention as this period is marked with onset of menarche. From the menarche, all the Girls have to face menstruation and its problems from which no adolescent girl can escape and hence menstrual hygiene is an issue that every girl and woman has to deal with in her life.

But there is lack of awareness on the process of menstruation, Physical and Psychological changes associated with puberty and proper requirements for managing menstruation due to the existing Indian cultural milieu.

The Issues regarding menstruation are never discussed openly, even after attainment of menarche very little information is given to the young girls about the physiological process and 


\section{ORIGINAL ARTICLE}

hygiene practices to be followed. The problems of poor menstrual hygiene management have been ignored and misunderstood by the society as well as policy makers till now.

OBJECTIVES: 1 . To know the Pattern of menstruation among adolescent girls.

2. To know the knowledge, Attitude and Practices of menstrual hygiene among adolescent girls.

METHODOLOGY: The present study was a cross-sectional study carried out among the adolescent girls studying in $8^{\text {th }} 9^{\text {th }}$ and $11^{\text {th }}$ classes of government school and colleges of urban field practice area of a medical college, west Godavari district.

From the list of Girls Inter colleges and high schools in urban field practice area, one high school and one Inter college was selected from simple random sampling method .Total strength of included high school students studying in $8^{\text {th }}, 9^{\text {th }}$ and inter college students studying in $11^{\text {th }}$ is 384 out of which only 375 have attained menarche hence 375 were included in the study. Tenth class students were excluded as the permission was not given to them because of their examination.

The study was carried out for 4 months. After taking permission from the ethical committee, the school authorities and college authorities were contacted and explained about the study. After obtaining the permission from school authorities, adolescent girls were interviewed after taking consent from them by using a Pre planned, pretested and structured questionnaire which was printed in local language (Telugu). Adolescent girls on whom the study was conducted were explained about the purpose of the study and assured of confidentiality. Girls were instructed on how to fill the questionnaire and explained about each question with the help of female teacher and made to answer all the questions on their own. The filled questionnaire with ticked answers is collected and then the collected data was entered on Microsoft excel and analyzed.

OBSERVATIONS AND RESULTS: A total of 384 girls studying in class $8^{\text {th }}$ 9 $^{\text {th }}$ and $11^{\text {th }}$ were approached in this study out of which only $9(2.34 \%)$ have not attained menarche, so they were excluded from the study. Finally the responses of 375 were evaluated. Most of the girls were in the age group of 16 years that is $41.33 \%$ and 17 years that is $18.4 \%$ of girls. Majority of the girls are Hindus (61.6\%) followed by Christians (36.8\%) and lastly occupied by Muslims (1.6\%).

$67.2 \%$ were from nuclear families and remaining $32.8 \%$ belong to joint families. Most of the girls belong to upper middle (58\%) and lower middle classes (38\%) according to B.G. Prasad classification ${ }^{1}$.

Table 1: Pattern of menstruation among adolescent girls

\begin{tabular}{|c|c|}
\hline Menstrual pattern in adolescent girls & No. (\%) \\
\hline Age at which Menarche attained & \\
$<12$ & $88(23.47)$ \\
$12-14$ & $267(71.2)$ \\
$>14$ & $20(5.33)$ \\
\hline Duration of blood flow attained & \\
$<2$ days & $5(1.33)$ \\
$3-5$ days & $321(85.6)$ \\
$>5$ days & $49(13.07)$ \\
\hline
\end{tabular}




\section{ORIGINAL ARTICLE}

\begin{tabular}{|c|c|}
\hline Length of cycle in days & $63(16.8)$ \\
$<28$ & $241(64.27)$ \\
$28-32$ & $71(18.93)$ \\
$>32$ & \\
\hline Quantity of blood flow & $257(68.53)$ \\
Normal & $86(22.93)$ \\
Excessive & $32(8.54)$ \\
\hline Scanty &
\end{tabular}

Above table shows $71.2 \%$ of girls have attained menarche in between $12-14$ yrs.13.07\% of girls have bleeding for more than 5 days and 22.93\% have excessive bleeding.

Table 2: Knowledge of adolescent girls in relation to menstruation.

\begin{tabular}{|l|c|}
\hline $\begin{array}{l}\text { Knowledge regarding menstruation after } \\
\text { attainment of menarche. }\end{array}$ & No. (\%) \\
\hline Menstruation is Physiological & $349(93.07)$ \\
\hline Route of Menstruation & $301(80.27)$ \\
Vaginal & $68(18.13)$ \\
Urethra & $2(0.5)$ \\
Anus- & $4(1.07)$ \\
Don't Know & \\
\hline Regarding Normal pattern of menstruation* & \\
Correct & $70(18.66)$ \\
Incorrect & $305(81.34)$ \\
\hline Regarding Menstrual Hygiene Practices & \\
Present & $268(71.47)$ \\
Absent & $107(28.5)$ \\
\hline
\end{tabular}

*Normal pattern of menstruation considered as 28+/- 7 days, with duration of 2-5 days and 2-4 pads used for blood adsorption.

The above table shows that $80.27 \%$ knew correctly that vagina is the route of transmission, only $18.66 \%$ have correct opinion about normal pattern of menstruation, $71.47 \%$ knew regarding menstrual hygiene practices.

Before attainment of Menarche only $6.13 \%$ had some idea regarding menstruation.

Table 3: Association between knowledge and Education.

\begin{tabular}{|c|c|c|c|c|}
\hline \multirow[t]{2}{*}{ Education } & \multicolumn{2}{|c|}{$\begin{array}{c}\text { Knowledge regarding pattern } \\
\text { of menstruation }\end{array}$} & \multicolumn{2}{|c|}{$\begin{array}{c}\text { Knowledge regarding } \\
\text { menstrual Hygiene practices }\end{array}$} \\
\hline & Correct(No.) & Incorrect(No.) & Present(No.) & Absent(No.) \\
\hline $8^{\text {th }}$ & 10 & 24 & 12 & 22 \\
\hline $9^{\text {th }}$ & 12 & 68 & 36 & 44 \\
\hline $11^{\text {th }}$ & 48 & 213 & 221 & 40 \\
\hline Total & 70 & 305 & 268 & 106 \\
\hline Chi-square value & \multicolumn{2}{|c|}{8.16} & \multicolumn{2}{|c|}{71.82} \\
\hline P-Value & \multicolumn{2}{|c|}{ Less than 0.05} & \multicolumn{2}{|c|}{ Less than 0.05} \\
\hline
\end{tabular}


From the above table we can say that there is significant association of Knowledge of the students with education.

Table 4: Attitude of adolescent girls in relation to menstruation.

\begin{tabular}{|l|c|}
\hline \multicolumn{1}{|c|}{ Attitude towards menstruation } & No. (\%) \\
\hline Attitude immediately after attainment of & \\
menarche & \\
Angry - & $233(62.13)$ \\
Irritation - & $63(16.8)$ \\
Afraid- & $58(15.47)$ \\
Happy- & $20(5.33)$ \\
\hline Hesitation about discussion regarding & \\
menstrual problems & $325(86.67)$ \\
Present- & $50(13.33)$ \\
Absent - & \\
\hline Not Interested in learning regarding how & \\
to maintain menstrual hygiene & $72(19.2)$ \\
Not interested - & $303(80.8)$ \\
Interested - & \\
\hline
\end{tabular}

The above table shows that majority that is $62.13 \%$ were angry immediately after attainment of menarche $86.6 \%$ hesitate to discuss regarding menstruation problems but $80.8 \%$ are interested in learning how to maintain menstrual hygiene.

Table 5: Practices of menstrual hygiene.

\begin{tabular}{|c|c|}
\hline Practice in relation to menstrual hygiene & No. (\%) \\
\hline $\begin{array}{l}\text { Adsorbent used in relation to menstruation } \\
\qquad \begin{array}{c}\text { Sanitary Pad } \\
\text { New Cloth } \\
\text { Old Cloth }\end{array}\end{array}$ & $\begin{array}{l}279(74.4) \\
61(16.27) \\
35(9.33)\end{array}$ \\
\hline $\begin{array}{l}\text { Supply of sanitary pad } \\
\qquad \begin{array}{l}\text { Purchase } \\
\text { Free supply }\end{array}\end{array}$ & $\begin{array}{c}268(98.13) \\
11(1.87)\end{array}$ \\
\hline $\begin{array}{l}\text { Place of drying, if cloth is used } \\
\text { Sundry } \\
\text { Private place }\end{array}$ & $\begin{array}{l}24(25) \\
72(75)\end{array}$ \\
\hline Hand washing practices during change of sanitary pad & $372(99.2)$ \\
\hline
\end{tabular}




\section{ORIGINAL ARTICLE}

\begin{tabular}{|c|c|}
\hline Genital hygiene practices $^{*}$ & $369(98.3)$ \\
Practiced & $6(1.07)$ \\
No of times - zero times & $102(27.73)$ \\
$<3$ times & $267(71.20)$ \\
$>3$ times & $375(100)$ \\
\hline Use of washed clothes and under garments & $48(12.8)$ \\
Type of Disinfectant used & $256(68.27)$ \\
Dettol & $71(18.93)$ \\
Soap & \\
Only water & $210(56)$ \\
No & $165(44)$ \\
\hline Yes & \\
\hline
\end{tabular}

* Cleaning the genitals with soap and water

Even now 9.33\% use old cloth during menstruation and out of those who use cloth 75\% dry in private places which is unhygienic. Regarding genital hygienic practices only $27.73 \%$ wash the genitals ideally for 3 times. $44 \%$ stain their clothes during menstruation frequently.

Table 6: Information regarding method of disposal of sanitary pad.

\begin{tabular}{|c|c|}
\hline Disposal of pads & No. (\%) \\
\hline Burn & $94(25.07)$ \\
\hline Clean and reuse & $6(1.6)$ \\
\hline Direct disposal in Dust bin & $92(24.54)$ \\
\hline Flush & $22(5.87)$ \\
\hline Wrap in paper or plastic cover and throw in dustbin & 161(42.94) \\
\hline Total & $375(100)$ \\
\hline
\end{tabular}

Regarding disposal of pads $25.07 \%$ burn the pads and $42.94 \%$ wrap the pad and throw in the dust bin in total $68.01 \%$ dispose the pad in the correct method.

Table 7: Sources of Menstruation:

\begin{tabular}{|l|c|}
\hline \multicolumn{2}{|l|}{$\begin{array}{c}\text { Awareness regarding menstrual hygiene is gained by } \\
\text { No (\%) }\end{array}$} \\
\hline Friends & $20(5.33)$ \\
\hline Mother & $310(82.67)$ \\
\hline Sister & $24(6.4)$ \\
\hline Relatives & $2(0.53)$ \\
\hline Teacher & $8(2.13)$ \\
\hline Health worker & $11(2.93)$ \\
\hline Media & $0(0)$ \\
\hline Total & $375(100)$ \\
\hline
\end{tabular}




\section{ORIGINAL ARTICLE}

Majority that is for $82.67 \%$, Mother was the first person to inform regarding menstrual hygiene followed by sister and friends.

DISCUSSION: In the present study, age of menstruating girls ranged from 13-17 yrs with maximum number of girls in the age group of 16 yrs and 17 yrs. Similar study was conducted by Dasgupta etal ${ }^{5}$, who reported that the age of menstruating girls ranged from 14-17 yrs with maximum number of girls between 14 \& 15 yrs.

In the present study, the mean age of menarche of the respondents was 13.13 yrs which is similar to the study conducted by Juyal et $\mathrm{al}^{3}$ where the mean age of menarche was $12.9 \mathrm{yrs}$, similar findings are by Dasgupta and Sarkar et $\mathrm{al}^{5}$ study also and comparatively a greater age of menarche was reported by Abhay et $\mathrm{al}^{2}$ that is 14.25 yrs.

Duration of blood flow is 3-5 days in $85.6 \%$ of the Respondents, and more than 5 days in $13.07 \%$ of Individuals .Similar observations were found in Keerti et al ${ }^{4}$ where $76.65 \%$ of girls reported blood flow between 3-5 days, Abhay et al $^{2}$ study shows for $70.63 \%$ of individuals, 3-5 days as period of blood flow and more than 5 days in $10.33 \%$ of Individuals. Amount of blood loss during menstruation was normal in $68.53 \%$ of girls and excessive in $22.93 \%$ of girls where as in Abhay et $\mathrm{al}^{2}$ study, $56.33 \%$ have normal bleeding and $17.67 \%$ have excessive bleeding.

In the present study only $6.13 \%$ knew about menstruation before attainment of menarche, very few knew about menstruation compared to Dasgupta etal ${ }^{5}$ study where knowledge is 32 . $5 \%$, Keerti et $\mathrm{al}^{4}$ study it is $36.19 \%$ and in Juyal et $\mathrm{al}^{3}$ study it is $64.5 \%$. But ideally each and every girl child should be aware about menstruation before attainment of menarche. In the present study large proportion of girls that is $93.87 \%$ of girls are not aware, about menstruation, this may be due to ignorance or shyness of the mothers to teach the children.

Now coming to the knowledge about menstruation after attainment of menarche, Pretty high percentage of individuals that is $93.07 \%$ of girls have a correct opinion that menstruation is physiological compared to other studies that is in Dasgupta etal ${ }^{5}$ study where it is only $86.25 \%$, In Juyal et $\mathrm{al}^{3}$ study only $11.5 \%$ knew that menstruation is Physiological.

Regarding route of menstruation, $80.27 \%$ of girls knew that vagina is the route compared to $29.1 \%$ in Juyal et $\mathrm{al}^{3}$ study, In the present study only $18.66 \%$ of girls knew regarding normal Menstrual cycle that is $28+/-7$ days, with duration of 2-7 days and utilization of 2-4 pads per day, very few knew regarding normal menstrual cycle compared to study conducted by Shuba dube et al 8 where 89 percent of urban and 72 percent of rural respondents knew regarding physiological menstrual cycle. Luckily high percentage that is $71.47 \%$ of individuals knew about maintenance of menstrual hygiene, this may be due to teaching in school regarding menstrual hygiene and due to inclusion in the secondary school syllabus.

Overall in the Present study practices to maintain menstrual hygiene is good, pretty high percentage that is $74.4 \%$ of girls use sanitary pad as an adsorbent compared to Dasgupta et etal ${ }^{5}$ study where $11.25 \%$ girls use sanitary pad and in Juyal et al $^{3}$ study where $38.4 \%$ adolescent girls use sanitary pads. $25.6 \%$ use old cloth in our study quite less compared to Keerthi et al ${ }^{4}$ study where $34.63 \%$ girls have reported old clothes during menstruation. Out of those who use cloth, $75 \%$ dry in private place similar to the study conducted by Juyal et $\mathrm{al}^{3}$ where $72.2 \%$ dry in private places. Hand washing, Genital hygiene and Personal hygiene practices are quite good, with more than 98\% practicing hygienic practices which is quite good compared to Abhay et al $^{2}$ study and in Mansoura, 


\section{ORIGINAL ARTICLE}

Egypt by El-Gilany et $a^{6}$ study where hygienic practices are $34.33 \%$.In the present study, Soap/dettol was used for cleaning of genitals by $81.07 \%$ of individuals which is quite good compared to Abhay et $\mathrm{al}^{2}$ study where the use is $59.33 \%$.

$1.66 \%$ reuse cloth during menstruation quite a good sign compared to Abhay et al2 study where $40.33 \%$ re use cloth during menstruation

Regarding attitude maximum that is $62.13 \%$ were angry immediately after attainment of menarche and in Abhay et al $^{2}$ study maximum that is $43.67 \%$ of girls were scared at the onset of menarche.86.67\% hesitate to discuss regarding menstrual problems, hesitation and shyness is quite high compared to Abhay et al ${ }^{2}$ study where it is only $28.67 \%$.Pretty high percentage that is $80.8 \%$ of girls are interested in learning regarding how to maintain menstrual hygiene.

Only $68.01 \%$ satisfactory dispose the sanitary pad comparatively little better than Abhay et $\mathrm{al}^{2}$ study where it is $56.57 \%$.Similar findings are reported in the study of Dasgupta A and Sarkar M etal $^{5}$

Maximum no of girls that is $82.67 \%$ were aware regarding menstruation by their mother as the first informant which shows that the communication of the mother with the daughter is quite good compare to other studies that is in Keerthi et $\mathrm{al}^{4}$, mother is the first informant in $61.29 \%$, Dasgupta etal ${ }^{5}$ study it is $37.5 \%$, In Abhay et $\mathrm{al}^{2}$ study, it is $40.67 \%$, In El-Gilany et $\mathrm{al}^{6}$, mass media was the main source of information, Juyal et $\mathrm{al}^{3}$ study, friends were the first informant that is for $31.8 \%$.

CONCLUSIONS: $71.2 \%$ of girls have attained menarche at the age of 12-14 yrs. Quite high percentage of girls that is $22.93 \%$ are suffering from menorrhagia. Pretty good percentage that is $80.27 \%$ of girls knew that vagina is the route of menstruation and only $18.66 \%$ of girls knew, regarding the normal pattern of menstruation. Although $86.67 \%$ hesitate to discuss regarding menstrual problems but $80.8 \%$ are interested in learning how to maintain menstrual hygiene. Overall menstrual hygiene practices are quite good with $74.4 \%$ practice menstrual hygiene and $98 \%$ practicing hand washing, personal hygiene and menstrual hygiene.

\section{REFERENCES:}

1. Shankar reddy, Arlappa.N. An updated Prasad's socio economic status classification for 2013.International Journal of research and development of Health.2013:26-27.

2. Abhay. B., Naveeta. K., Gargi. A., Ramchandra. C., A cross sectional study on awareness regarding safe and hygienic practices amongst school going adolescent girls in rural area of Wardha district, India. Global journal of health science. October 2010; vol 2: No 2:225-231

3. Juyal R., Kandpal S D., Semwal J., Negi K S., Practices of menstrual hygiene among adolescent girls in district of Uttarakand. Indian journal of community health, Vol24.No.2, 2012:124-128

4. Keerti.J., Pravin Y., A community based study on menstrual hygiene among adolescent girls. Indian journal of Maternal and child health, 2011 Jul-Sep; 13(3):2-6

5. Dasgupta A., Sarkar M., Menstrual hygiene: How hygienic is adolescent girl? Indian J Community Medicine. 2008; 33(2):77-80.

6. El-Gilany A.H., \& Badawi K., Menstrual hygiene among adolescent schoolgirls in Mansoura, Egypt. Reproductive Health Matters.2008; 13:147-52. 


\section{ORIGINAL ARTICLE}

7. Khanna A., Goyal RS., Bhawsar R., Menstrual practices and reproductive problems: a study of adolescent girls in Rajasthan. J Health Manag. 2005; 7:91-107.

8. Shuba dube., Kirti Sharma., Knowledge Attitude and Practice regarding reproductive health among urban and rural girls: A Comparative study. Ethno Med; 6(2):85-94(2012).

\section{AUTHORS:}

1. Shridevi K.

2. Padma K.

\section{PARTICULARS OF CONTRIBUTORS:}

1. Assistant Professor, Department of Community Medicine, ASRAM.

2. Assistant Professor, Department of Community Medicine, ASRAM.

\section{NAME ADDRESS EMAIL ID OF THE} CORRESPONDING AUTHOR:

Dr. Shridevi. K, Assistant Professor, Department of Community Medicine, ASRAM Medical College,

Malkapuram, Eluru.

Email- srinushri1509@yahoo.co.in

Date of Submission: 05/08/2013.

Date of Peer Review: 06/08/2013.

Date of Acceptance: 16/08/2013.

Date of Publishing: 21/08/2013 